\title{
Representações sociais da Libras como disciplina obrigatória por atores de escola pública e privada no Munícipio de Guarabira-PB
}

\author{
Social representations of Libras as a mandatory subject by actors from schools in public and \\ private schools in the Municipality of Guarabira-PB \\ Representaciones sociales de Libras como asignatura obligatoria por actores de escuelas en escuelas \\ públicas y privadas del Municipio de Guarabira-PB
}

Recebido: 28/12/2020 | Revisado: 03/01/2021 | Aceito: 07/01/2021 | Publicado: 08/01/2021

\author{
Amanda Berto Ribeiro de Oliveira \\ ORCID: https://orcid.org/0000-0003-3955-5161 \\ Universidade Federal da Paraíba, Brasil \\ E-mail: nandab.ribeiro@hotmail.com \\ Giovanna Barroca de Moura \\ ORCID: https://orcid.org/0000-0001-7970-4323 \\ Universidade Federal da Paraíba, Brasil \\ E-mail: giovannabarroca@gmail.com \\ Carlos da Silva Cirino \\ ORCID: https://orcid.org/0000-0003-4468-3686 \\ Universidade Estadual da Paraíba, Brasil \\ E-mail: carlos-cirino@hotmail.com \\ Wagner da Silva Santos \\ ORCID: https://orcid.org/0000-0003-4091-5021 \\ Universidade Federal da Paraíba, Brasil \\ E-mail: wagnerfiel11@ @otmail.com \\ Ércules Laurentino Diniz \\ ORCID https://orcid.org/0000-0003-4932-8915 \\ Universidade Federal da Paraíba, Brasil \\ E-mail: ercules.diniz@hotmail.com
}

\begin{abstract}
Resumo
O presente estudo objetivou apreender as representações sociais dos alunos e professores da educação básica do Município de Guarabira/PB no que diz respeito à inclusão da disciplina Libras nas escolas. Como aporte teórico optou-se pela teoria das representações sociais, por permitir compreender como os sujeitos sociais concebem acontecimentos do cotidiano - informações, sentimentos e experiências sociais - relacionados à área da surdez. Como suporte metodológico foi realizado uma pesquisa de campo, de abordagem qualitativa e quantitativa composta por uma amostra não-probabilística e de conveniência, formada por 50 sujeitos, sendo 22 alunos do curso de pedagogia e 18 professores da educação básica realizada em escolas pública e privada. Para a coleta dos dados utilizou-se um questionário sócio demográfico e a técnica da Associação Livre de Palavras cujos estímulos indutores foram: surdo; libras; inclusão social do surdo; inclusão da disciplina de libras na escola. Os dados provenientes da associação livre foram processados e analisados pelo software Tri-Deux-Mots, por meio da análise fatorial de correspondência. O estímulo "Libras" foi representado como: "algo produzido pelas mãos", uma "linguagem de sinais", que proporciona "ensino e ajuda", sendo, portanto, uma "linguagem gestual". Os resultados apontaram a relevância do estudo das representações sociais no que tange sua importância e obrigatoriedade no aprendizado da Libras. Proporcionou uma melhor compreensão na urgência de debates e discussões sobre a valorização e popularização para a sociedade, bem como na capacitação e ampliação didático-pedagógico enquanto ferramenta de ensino e aprendizagem no universo pesquisado.
\end{abstract}

Palavras-chave: Representações sociais; Língua brasileira de sinais; Inclusão educacional.

\begin{abstract}
The present study aimed to apprehend the social representations of students and teachers of basic education in the Municipality of Guarabira / PB with regard to the inclusion of the discipline Libras in schools. As a theoretical contribution, the theory of social representations was chosen, as it allows understanding how social subjects conceive everyday events - information, feelings and social experiences - related to the area of deafness. As a methodological support, a field research was carried out, with a qualitative and quantitative approach, composed of a non-probabilistic and convenience sample, formed by 50 subjects, 22 students of the pedagogy course and 18 teachers of basic education held in public and private schools. For data collection, a socio-demographic questionnaire and the Associação Livre de Palavras technique were used, whose inducing stimuli were: deaf; pounds; social inclusion of the deaf; inclusion of the discipline of pounds in the school. The data from the free association were processed and
\end{abstract}


analyzed by the Tri-Deux-Mots software, through the correspondence factor analysis. The "Libras" stimulus was represented as: "something produced by the hands", a "sign language", which provides "teaching and help", being, therefore, a "sign language". The results pointed out the relevance of the study of social representations in terms of their importance and obligation in learning Libras. It provided a better understanding in the urgency of debates and discussions about the valorization and popularization for society, as well as in the didactic-pedagogical training and expansion as a teaching and learning tool in the researched universe.

Keywords: Social representations; Brazilian sign language; Educational inclusion.

\section{Resumen}

El presente estudio tuvo como objetivo aprehender las representaciones sociales de estudiantes y docentes de educación básica del Municipio de Guarabira / PB con respecto a la inclusión de la disciplina Libras en las escuelas. Como aporte teórico se eligió la teoría de las representaciones sociales, ya que permite comprender cómo los sujetos sociales conciben los hechos cotidianos --información, sentimientos y vivencias sociales-- relacionados con el área de la sordera. Como soporte metodológico se realizó una investigación de campo, con enfoque cualitativo y cuantitativo, compuesta por una muestra no probabilística y de conveniencia, conformada por 50 sujetos, 22 alumnos del curso de pedagogía y 18 docentes de educación básica impartidos en colegios públicos y privados. Para la recolección de datos se utilizó un cuestionario sociodemográfico y la técnica Associação Livre de Palavras, cuyos estímulos inductores fueron: sordo; libras inclusión social de los sordos; inclusión de la disciplina de libras en la escuela. Los datos de la asociación libre fueron procesados y analizados por el software Tri-Deux-Mots, a través del análisis factorial de correspondencia. El estímulo "Libras" se representó como: "algo producido por las manos", una "lengua de signos", que brinda "enseñanza y ayuda", siendo, por tanto, una "lengua de signos". Los resultados señalaron la relevancia del estudio de las representaciones sociales en términos de su importancia y obligación en el aprendizaje de Libra. Brindó una mejor comprensión en la urgencia de debates y discusiones sobre la valorización y popularización para la sociedad, así como en la formación y expansión didáctico-pedagógica como herramienta de enseñanza y aprendizaje en el universo investigado.

Palabras clave: Representaciones sociales; Lengua de señas brasileña; Inclusión educativa.

\section{Introdução}

A surdez não pode ser considerada como algo novo. Isto porque desde os registros bíblicos, os sujeitos surdos são citados. O livro de Levítico (19:14) traz o surdo como ser que não deve ser amaldiçoado, ou seja, devem ser tratados com igualdade. Somente 2 mil anos depois houve o reconhecimento das línguas de sinais como uma nova possibilidade de compreensão do mundo.

A Língua Brasileira de Sinais, usualmente conhecida como Libras, sancionada no Brasil pela LEI 10.436/2002 é reconhecida como meio legal de comunicação e expressão. É classificada como a segunda língua oficial do país, apesar deste importante passo histórico, mesmo que tardio, ainda carece de incentivos públicos que mobilizem o acesso ao aprendizado no universo educacional. O debate e a discussão para criação de políticas, programas e projetos, a nosso ver, se fazem necessária e urgente pelas dimensões continentais do Brasil e, ainda, as poucas pessoas com o domínio da língua. A nosso ver, sem o acesso, se reduz significativamente a sua valorização e popularização. E ainda, não menos relevante, deixa de lado pessoas e não aproxima os processos comunicacionais, interativos e inter-humanos, tão caros, nos processos didáticos de ensinoaprendizagem.

O objetivo principal deste estudo é apreender as representações sociais dos alunos e professores da educação básica do Município de Guarabira/PB no que diz respeito à inclusão da disciplina Libras nas escolas. Como aporte teórico, optamos pela teoria Moscoviciana, por esta permitir compreender como os sujeitos sociais apreendem os acontecimentos do cotidiano, as informações que circulam, bem como os sentimentos e experiências de vida compartilhada, através de diferentes modalidades de comunicação, diretamente relacionadas ao contexto social no qual os indivíduos estão inseridos. "As representações podem se tornar indicadores indiretos de como os sujeitos se definem e como o outro o define em relação a esse objeto" (Coutinho \& Saldanha, 2005, p. 26).

Desta forma, Sêga (2000) destaca: 
as representações sociais se apresentam como uma maneira de interpretar e pensar a realidade cotidiana, uma forma de conhecimento da atividade mental desenvolvida pelos indivíduos e pelos grupos para fixar suas posições em relação a situações, eventos, objetos e comunicações que lhe concernem (p. 2).

É neste contexto que os esforços deste trabalho buscam instigar a inclusão da disciplina de Libras nas escolas desde os anos iniciais, com o propósito de conhecer e estudar as representações dos docentes e discentes frente à instituição escolar e sua estrutura organizacional.

A educação tem sido um campo fértil em que a noção de representação social vem sendo privilegiada. Para Gilly (2001), o interesse para a compreensão dos fenômenos da educação consiste nos significados sociais atribuídos ao processo educativo, isto porque "é possível, por meio das representações sociais, explicar mecanismos pelos quais fatores propriamente sociais agem sobre o processo educativo e influenciam seus resultados" (p. 321).

Apesar dos estudos sobre representações sociais acerca da Libras não serem comuns, também não têm sido tão escassos. Em nossa revisão de literatura, encontramos a pesquisa de Costa e Kelman (2013); Junqueira (2014); Castro (2016); Souza e Silva (2018).

\section{Aspectos Fundamentais da Surdez}

O ser humano percebe o mundo através dos sentidos, é por meio deles, que as informações são captadas para a formação de sua experiência (Oliveira, 2012). Quando, por determinado motivo, acontece a redução ou a perda de algum sentido, ele utiliza os demais para apreender as informações. O surdo não consegue ouvir através da audição, mas é capaz de "ouvir com os olhos" e de se emocionar pelas mãos.

De acordo com a Organização Mundial da Saúde (2000), 10\% da população possui algum tipo de deficiência, entre essa porcentagem $1,5 \%$ tem uma limitação na audição. A palavra surdez se refere a algum tipo de perda de audição, seja parcial ou total. A perda da audição pode ser temporária ou definitiva.

Segundo Davis e Silverman (1970), a surdez é algo incapacitante, ou seja, o surdo é incapaz de desenvolver a linguagem oral pelo fato de não ouvir. Desse modo, os mesmos autores afirmam que os graus de surdez são tão elevados que os impedem de ouvir os sons de maneira adequada, escutando apenas barulhos, sem a aptidão de identificá-los. As perdas de audição são maiores que 93 decibéis. Em vista disso, justifica-se o porquê de ser inadequado nomear um surdo de "surdomudo" ou "mudinho", pois ele dispõe de voz, apenas não decodifica as palavras pelo fato de não ouvi-las, sendo, na maioria dos casos, não oralizado.

As perdas auditivas ocorrem de diversas maneiras e por inúmeras causas. Desta forma, Lafon (1989) afirma que as explicações etiológicas provêm de diferentes origens: genéticas, infecciosas, mecânicas ou tóxicas, além da desnutrição e outras doenças. Pode ocorrer, ainda, durante a gravidez e nos períodos que antecedem ou sucedem o nascimento.

A surdez pode ser congênita, tanto quando ocorre alguma reação com a mãe durante o período gestacional, quanto por questões genéticas ou pelo fato da criança não ter tido contato com a língua oral. Neste caso, denominada de surdez prélingual. Também pode ser adquirida, através de alguma doença que causa a perda auditiva, denominada de surdez pós-lingual, pois o indivíduo já havia tido contato com a língua oral (Oliveira, 2012).

A língua de sinais é o elemento mediador entre o surdo e o meio social em que ele vive. É por intermédio dela que os surdos podem demonstrar sua capacidade de interpretação do mundo, desenvolvendo estruturas mentais em níveis mais elaborados (Skliar, 1997). Partindo desse pressuposto, entendemos que se um surdo não decodifica as palavras sua língua materna não pode ser a língua portuguesa, pois, assim como nós ouvintes, necessitamos da língua portuguesa para a formação de nossa identidade. O surdo necessita da língua de sinais, porque é a partir dela que ele expressa seus sentimentos, compreende o mundo e dar sentido às suas vivências, - consegue se comunicar. 


\section{Libras}

A partir do bilinguismo, a Libras passa a ser assumida como a primeira língua do surdo. Dessa forma, é a partir do século XVII que há o reconhecimento da língua de sinais possuidora de características e estrutura gramatical próprias, distinguindo-se de "linguagem". Assim, a Libras é definida como um sistema abstrato de regras gramaticais em seus diversos planos: fonológico (sons), morfológico (formas), sintático (estruturação frasal) e semântico-pragmático (significado e uso), podendo ser orais-auditivas ou espaço-visuais (Veodato \& Vágula, 2014).

A Língua Brasileira de Sinais, assim como qualquer outra língua, possui uma estrutura gramatical própria, diferenciando-se no que diz respeito ao canal espaço-visual. É, portanto, utilizada pelo surdo como primeira língua e indispensável para a aquisição do conhecimento pela criança surda, assim como afirma Sá (2002):

O uso da língua de sinais é uma característica identitária da maior importância. Os surdos organizados em comunidades consideram o uso da língua de sinais uma evidência de pertença à comunidade surda. A língua é uma atividade em evolução, assim como o é a identidade (p. 130).

Quadros e Karnopp (2004) apontam que Stokoe, em 1960, comprovou que a língua de sinais atendia a todos os critérios linguísticos de uma língua genuína, no léxico, na sintaxe e na capacidade de gerar uma quantidade infinita de sentenças. Concluiu, ainda, que os sinais não eram imagens, mas símbolos abstratos e complexos, através da comprovação de que cada sinal apresentava pelo menos três partes independentes e com um número ilimitado de combinações em analogia com os fonemas da fala: a localização, a configuração de mãos e o movimento.

A Libras é a língua natural do surdo, que garante a possibilidade de se expressar, compreender o mundo e agir sobre ele, por meio da utilização das mãos. É por intermédio da Libras que as pessoas surdas organizam seus pensamentos, desenvolvem suas estruturas cognitivas, criam suas representações e constituem a realidade em que vivem, formando uma identidade social própria (Castro, 2016).

Ademais, podemos constatar que dentro dos aspectos linguísticos da Libras existem cinco parâmetros necessários para a execução do sinal. Fernandes (2003) define-os: 1) a configuração de mãos, ou seja, a forma que a mão assume durante a realização do sinal, podendo ser utilizada tanto a mão dominante, quanto as duas mãos, a depender de cada sinal; 2) o ponto de articulação, que é o lugar onde incide a mão predominante configurada, podendo tocar em alguma parte do corpo ou em um espaço neutro; 3) movimento, considerado o deslocamento da mão no espaço durante a realização do sinal; 4) orientação/direção das mãos, ou seja, os sinais podem ter uma direção e a inversão destas pode significar ideia de oposição; e 5) expressão facial e/ou corporal que tem na sua configuração o traço diferenciador, pois demonstra a intensidade do sinal, contribuindo para a atribuição do sentido exato dos sinais.

Portanto, a Libras se configura como a ponte de comunicação entre surdos-surdos e surdos-ouvintes. A inserção da língua nas escolas, objetivando que o maior número de pessoas possa dominá-la, opera na superação de obstáculos e na inclusão social, fazendo com que o surdo se sinta integrado e acolhido pela sociedade, diminuindo, dessa forma, as práticas discriminatórias.

\section{Representações Sociais e a Inclusão da Disciplina da Libras}

A Teoria das Representações Sociais, propagada através dos estudos psicossociais de Moscovici, é utilizada neste trabalho com o objetivo de compreender o que pensam os pedagogos e futuros pedagogos sobre a disciplina obrigatória de Libras nas escolas. Entendemos que as diferentes concepções e visões sobre o nosso objeto de estudo se dá pela interpretação de cada indivíduo, tendo em vista que cada um enxerga e compreende um determinado objeto de modo distinto. Assim, a 
Teoria das Representações Sociais configura-se enquanto aporte fundamental em nossa pesquisa para entendermos o que determinado grupo de pessoas pensam a respeito de um objeto.

Em Minayo (2008) vemos que as representações sociais mostram a visão de mundo de determinada época. Desta forma, a representação social compreende a visão dos discentes e docentes da área da pedagogia acerca da Libras enquanto disciplina obrigatória nas escolas. É importante destacar que "com o ensino da Libras os alunos aprenderiam o básico da comunicação dos surdos e assim, estariam mais familiarizados quando for incluído um aluno ou futuramente um colega de trabalho". (Silva, 2016, p. 55).

Moscovici (2012), em seus estudos psicossociais, afirma que a Teoria das Representações Sociais está presente em todas as interações humanas, de modo que tudo que fazemos é considerada uma representação social. Partindo desse pressuposto, Jodelet (2001) conceitua como um ato de pensamento pelo qual um sujeito se reporta a um objeto. Este pode ser tanto uma pessoa, quanto uma coisa, um acontecimento material, psíquico ou social, um fenômeno natural, uma ideia, uma teoria, etc.

Nesse sentido, podem ser entendidas como conjuntos simbólicos e práticos cujo status é o de uma construção e não de uma reprodução ou reação a estímulos exteriores, caracterizando-se pelo uso e seleção de informações, a partir do repertório circulante no arcabouço social, destinadas à interpretação e à elaboração do real. Assim, "representar uma coisa, um estado, não é só desdobrá-lo, repeti-lo ou reproduzi-lo, é reconstituí-lo, retocá-lo, modificar-lhe o texto" (Moscovici, 2012, p. 54).

Em face dessas características, alguns autores preconizam que a teoria é bastante pertinente para a compreensão da dinâmica social, uma vez que é na relação com o outro que as representações são construídas (Sá, 2001; Saraiva, 2007). A este respeito, Félix e Santos (2011) asseguram que as representações sociais são criadas pela necessidade de saber como se ajustar e se comportar no mundo, de forma a dominá-lo física ou intelectualmente, assim como pela habilidade de identificar e resolver os problemas que se apresentam. Para Jodelet (2001), tais afirmações significam o fato de que as representações sociais são basilares, pois "sempre há necessidade de estarmos informados sobre o mundo à nossa volta" (p. 17).

O estudo que envolve as representações sociais desenvolve-se sob a análise das características que sustentam a ideia de que as representações são uma forma de conhecimento e classificação que utiliza suportes comportamentais e materiais da linguagem. Como Sá (1998) nos orienta, a representação social "é um saber efetivamente praticado, que não deve ser apenas suposto, mas sim detectado em comportamentos e comunicação que de fato ocorram sistematicamente" (p. 50).

Destarte, esta pesquisa focalizou na socialização do conhecimento como fator de importância para a construção da realidade social. Assim, além de analisar o conhecimento do universo reificado, buscou apreender as representações sociais, enquanto produto e processo, com relação à inclusão da disciplina de Libras nas escolas que são produzidas e veiculadas no dia a dia. De acordo com Saraiva (2010), a intervenção do conhecimento científico no cotidiano desempenha influência na construção das teorias do senso comum (universo consensual) que os grupos tramam acerca dos objetos de importância para as suas vidas.

No que concerne às investigações teórico-metodológico das representações sociais acerca da língua de sinais elaborada por docentes e discentes, podemos destacar algumas pesquisas semelhantes no trato da inclusão da disciplina de Libras nas escolas. Destacamos a pesquisa de Costa e Kelman (2013) que teve como objetivo principal analisar as representações sociais dos alunos surdos e profissionais do curso de graduação em Letras - Libras na modalidade EaD Educação à Distância. Os resultados desta pesquisa mostram que os participantes relataram a importância da educação bilíngue para o surdo e que esse modelo de curso faz com que eles se sintam valorizados, capazes e iguais.

Outra pesquisa similar foi o estudo de Junqueira (2014) que teve como objetivo investigar a representação educacional e social do instrutor Surdo para uma Escola Municipal de Surdo de Gado Bravo (EMSGB). Os resultados mostraram que a instrutora surda se constitui como um modelo positivo de identidade e de representações sociais, 
desempenhando papel fundamental na disseminação da Libras ao povo surdo e de articuladora para o desenvolvimento de uma nova representação sócio educacional dos estudantes surdos do Município de Gado Bravo, Paraíba.

Já o estudo de Castro (2016) teve como objetivo principal conhecer a importância atribuída à Libras por esses sujeitos na construção de uma identidade positiva. Os pesquisados atribuem grande importância ao domínio dessa língua como fator de cidadania, sendo este essencial à própria formação da comunidade surda, pois modifica sua auto percepção identitária, atribuindo um valor positivo à condição surda.

Concernente, encontramos a pesquisa de Silva (2016), que muito se assimila ao nosso objeto de pesquisa, na qual teve por objetivo principal pesquisar a importância de toda criança ter, ao menos, uma introdução à Língua Brasileira de Sinais e, como resultado, obteve-se um cronograma, onde uma nova disciplina seria inserida no currículo escolar. Dessa forma, a disciplina Libras teria o objetivo de fazer com que as crianças e jovens tivessem um contato com as diversidades e aprendessem a respeitar as diferenças, além de prepará-los para a vida pessoal e profissional.

Outrossim, a pesquisa realizada por Souza e Silva (2018) analisa as representações sociais de professores sobre os artefatos culturais de estudantes surdos, verificando os elementos teóricos e conceituais das representações sociais no contexto educacional. Os resultados obtidos apontaram que as representações sociais dos professores estão relacionadas à concepção clínico-terapêutica da surdez, logo, suas práticas pedagógicas são antagônicas à valorização das especificidades da cultura surda.

Sendo assim, por meio do campo conceitual e metodológico das representações sociais, este estudo busca identificar as representações acerca da inclusão da disciplina de Libras nas escolas que estruturam o grupo de docentes e discentes que podem (ou não) se constituir em ancoragens facilitadoras de novas práticas.

\section{Procedimentos Metodológicos}

\subsection{Tipo de Estudo}

O objeto desta pesquisa são as representações sociais acerca da inclusão da disciplina de Libras nas escolas por discentes e docentes da educação básica da área da Pedagogia, baseada em uma pesquisa de campo, abalizado em uma abordagem multimétodo abalizados em um multimétodo ou metodologia mista de Creswell (2010) - que são escolhas de procedimentos técnicos, pautados nas decisões do pesquisador, no processo de coleta e análise. Fazem uso de informações qualitativas (textuais) e quantitativa (numéricas), podendo uma técnica ser complementar a outra - sentido de somar dados e análise - ou uma técnica ser suplementar a outra - sentido de acrescentar dados e análise.

Com o apoio metodológico qualitativo buscou-se o conhecimento das representações sociais dos participantes em relação aos construtos: surdo, Libras, inclusão social do surdo e inclusão da disciplina de Libras nas escolas, que serviram de fonte para a compreensão das vivências desses atores, identificando uma pluralidade de sentidos e significados e demonstrando uma diversidade de maneiras de compreendê-los e de explicá-los.

Com o quantitativo apreciou-se a amplitude e os limites de diversas variáveis sociodemográficas. Para Minayo (2002), apesar das diferenças, os métodos se complementam, pois alcançam o mesmo objeto de estudo, qual seja o conhecimento baseado em diferentes aspectos.

\subsection{Locus da pesquisa}

Esta pesquisa foi desenvolvida em uma instituição pública de ensino superior e em duas escolas da educação básica: pública e privada, todas localizadas na cidade paraibana de Guarabira/PB. A escola pública totaliza 309 alunos, sendo 4 estudantes surdos. No turno da manhã e tarde conta com 199 alunos no fundamental I e II, à noite funciona EJA com 110 estudantes. A escola possui 25 professores, 1 intérpretes de Libras e 2 salas de AEE. 
A escola privada funciona em dois turnos: manhã e tarde. No turno da manhã conta com 107 alunos matriculados e no turno da tarde com 184, totalizando 291 alunos. A instituição possui 26 professores. A escola não tem nenhum aluno surdo matriculado e não possui sala de AEE.

A universidade pública localizada no município paraibano de Guarabira, possui e 2.276 alunos distribuídos em cinco cursos de licenciatura: Pedagogia, Geografia, História e Letras. O curso de Pedagogia conta com uma equipe de 29 professores e 411 alunos cursando o curso de pedagogia.

\subsection{Instrumentos}

Os instrumentos utilizados foram: questionário sociodemográfico e o teste de Associação Livre de Palavra (ALP) com questões abertas quanto aos objetivos reportados. Realizados de forma individual, onde os principais estímulos foram surdo, Libras, inclusão social do surdo, inclusão da disciplina de Libras nas escolas, seus benefícios e necessidade, atenderam à representação de três grupos sociais: grupo 1 - alunos iniciantes do curso de Pedagogia; grupo 2 - alunos concluintes do curso de Pedagogia, ambos de uma universidade pública do referido município; e o grupo 3 - professores da educação básica, licenciados na área de Pedagogia, também da mesma cidade.

A primeira parte do instrumento foi composta pela ALP, no qual o sujeito teria que escrever até cinco palavras que lhe viesse à mente ao ouvir tal estímulo. Na segunda parte, responderam o questionário sociodemográfico, contendo as variáveis de identificação: sexo, idade, estado civil, entre outros.

\subsection{Perfil dos Participantes}

Participaram desta amostra 50 sujeitos. Observou-se que 44 são do sexo feminino; 29 declararam o estado civil solteiro; 19 discentes fazem parte do grupo de alunos iniciantes; 30 participantes retorquiram que sempre percebem a deficiência do outro e são empáticos; 30 responderam que se comunicam razoavelmente com um surdo e 34 afirmaram que não se sentiriam incluídos na sociedade se fossem surdos. No que concerne às possibilidades de aprender Libras, 26 destes sujeitos declararam que moderadamente poderiam aprender a língua de sinais e 25 afirmaram que se sentem parcialmente preparados para receber um aluno surdo em sala de aula.

Ao visualizar tais resultados podemos concluir que umas das características principais que um pedagogo ou futuro pedagogo precisa é a empatia diante da deficiência para poder atuar na educação. Para tanto, é necessário se capacitar sempre para melhor atender e trabalhar com seus alunos, com metodologias inclusivas, que garantam um melhor ensino-aprendizagem a partir da interação. Quanto as possibilidades de aprender mais uma língua e se sentir preparado para encontrar um deficiente auditivo, ainda há um certo bloqueio de acordo com as respostas dos participantes, alguns alegam o nível de dificuldade para aprender ou falta de tempo.

\subsection{Questionário Sócio demográfico}

Este instrumento foi utilizado com a intenção de obter um perfil característico da amostra, além de alcançar informações necessárias para a composição das variáveis fixas, utilizadas para o banco de dados processado pelo programa computacional software Tri-Deux-Mots.

\subsection{Técnica de Associação Livre de Palavras- ALP}

O instrumento que faz uso da técnica em questão foi originalmente desenvolvida por Jung, no início do século XX, nos moldes do diagnóstico clínico, com a função de "analisar a estrutura psicológica por meio das manifestações de condutas de reações, evocações, escolhas e criações, capazes de revelar a estrutura da personalidade” (Coutinho, 2005, p. 78). No 
entanto, foi Di Giácomo (1981) quem adaptou o instrumento como ferramenta de pesquisa passível de ser utilizada no campo de estudos em Psicologia Social, especificamente nas pesquisas ancoradas nos pressupostos teóricos e metodológicos das Representações Sociais (Nóbrega \& Coutinho, 2003; Sá, 1998).

Para o presente estudo, essa técnica foi utilizada com a intenção de identificar as dimensões latentes das representações através da configuração dos elementos que constituem as redes associativas dos conteúdos evocados em reação a cada construto, estímulo ou palavra indutora. Assim, a técnica mostra-se bastante pertinente para a proposta deste estudo pois, segundo Abric (1994), permite a "atualização de elementos implícitos ou latentes que seriam perdidos ou mascarados nas produções discursivas" (p. 66).

\subsection{Procedimentos para coleta e análise dos dados}

Após a coleta dos dados, as respostas referentes ao questionário sociodemográfico foram processadas pelo pacote estatístico Statistical Package for the Social Sciences (SPSS.21) para a elaboração de gráficos de frequência. Os dados advindos da técnica de associação livre de palavras foram processados pelo software Tri-Deux-Mots (Cibois, 1995) e analisados por meio da Análise Fatorial de Correspondência (AFC). Este tipo de análise permite a visualização gráfica da dinâmica de atração e distanciamento entre as modalidades de respostas face aos estímulos e características dos grupos. Por esta razão, adotamos esse meio com o propósito de depreender o eixos que explicam as modalidades de respostas dos sujeitos do estudo, mostrando estruturas constituídas do campo representacional simbolizado pelo gráfico e facilitando o estudo dimensional das representações sociais (Coutinho, 2005).

\section{Resultados e Discussões}

A seguir, serão apresentadas a análise e a discussão dos resultados obtidos pela aplicação do questionário sociodemográfico e da técnica de Associação Livre de Palavras.

\subsection{Resultados apreendidos pela Técnica de Associação Livre de Palavras e o Questionário sócio demográfico}

Apresentaremos, a seguir, os resultados alcançados através da aplicação do questionário sócio demográfico e da técnica de associação livre de palavras, com o intuito de utilizá-los como ferramentas para o acesso à investigação das representações sociais do surdo; Libras; inclusão do surdo; inclusão da disciplina de Libras na escola, formadas pelos alunos do primeiro e último período do curso de Pedagogia e professores da educação básica. Neste aspecto, serão ilustradas as características da amostra e, logo em seguida, serão explicitadas as evocações livres dos sujeitos face aos estímulos indutores, processadas por meio do programa computacional Tri-Deux-Mots.

\subsection{Associação Livre de Palavras e o Tri-Deux-Mots}

Com o propósito de apreender as representações sociais dos alunos do primeiro e último período do curso de Pedagogia e professores da educação básica acerca do objeto de interesse, os dados advindos da Associação Livre de Palavras foram processados no programa computacional Tri-Deux-Mots.

O referido programa foi utilizado com o propósito de representar graficamente a aproximação e o distanciamento entre as variáveis fixas e as variáveis de opinião apresentadas pelos jovens desta pesquisa. Tais variáveis foram constituídas a partir do questionário sociodemográfico e das evocações desses autores sociais face aos estímulos indutores na associação livre. A codificação dessas variáveis adotou o modelo apresentado na Figura 1. 
Figura 1. Codificação das variáveis fixas e de opinião utilizadas para a composição do banco de dados para o processamento de análise no software Tri-Deux-Mots.

\begin{tabular}{|c|}
\hline Variáveis de opinião - Estímulo indutores \\
1=Surdo; \\
$2=$ Libras; \\
$3=$ Inclusão do surdo; \\
$4=$ Inclusão da disciplina de Libras na escola \\
Variáveis Fixas \\
Alunos iniciantes \\
Alunos concluintes \\
Professores da educação básica
\end{tabular}

Fonte: Autores.

O processamento dos dados pelo software permitiu a Análise Fatorial de Correspondência (AFC) das evocações dos participantes frente aos estímulos indutores com as maiores cargas fatoriais coligadas às variáveis sociodemográficas já mencionadas (Coutinho, 2005; Saraiva, 2007).

Seguindo o modelo interpretativo proposto por Saraiva (2007), as discussões acerca do universo consensual dos discentes e dos docentes serão apresentadas no conjunto da análise e dos comentários sobre o plano fatorial de correspondência decorrente da análise efetuada no software Tri-Deux-Mots, de acordo com a Figura 2.

Figura 2. Evocações dos Participantes Quantos as Variáveis Fixas.

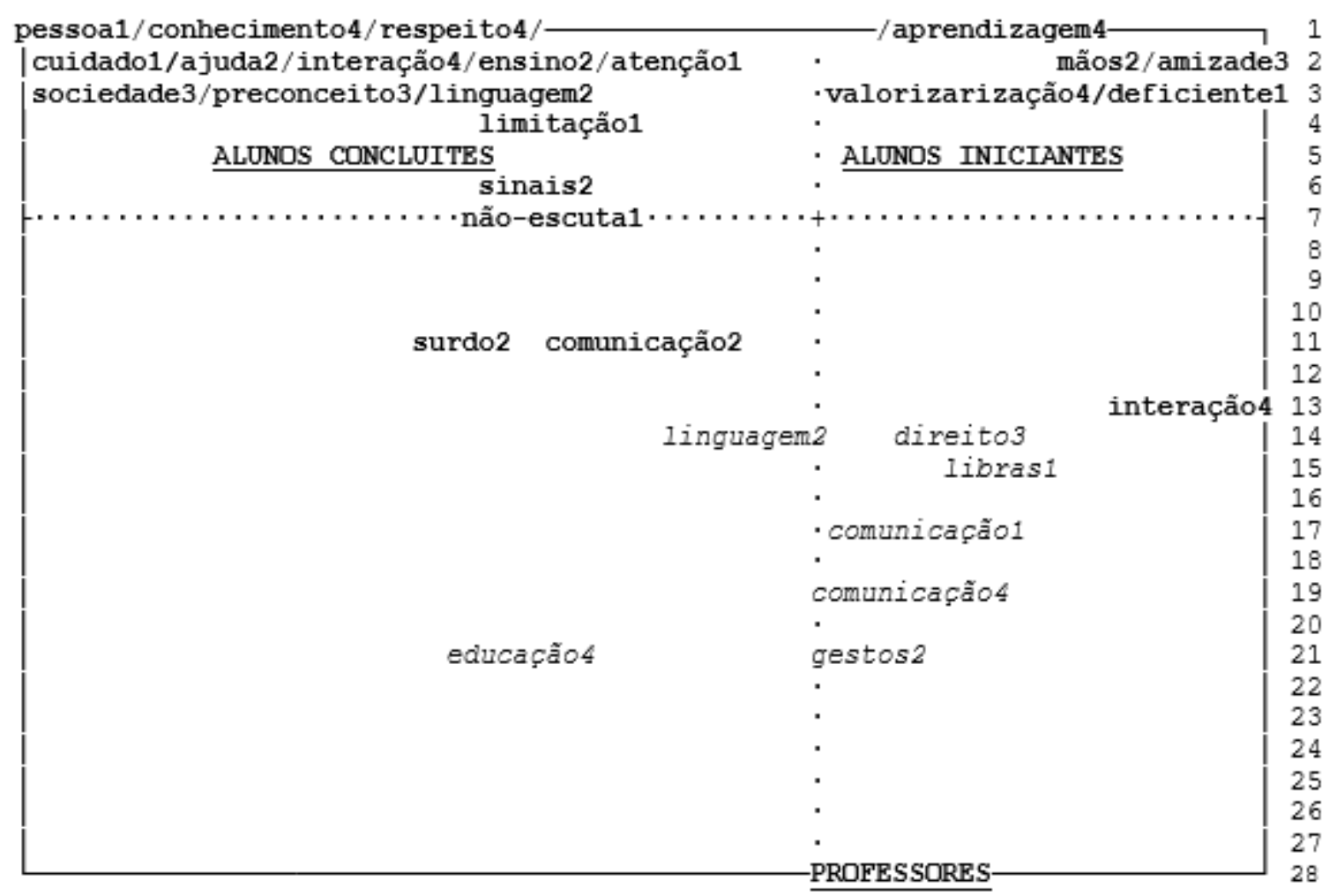

Legenda do Plano Fatorial:

Fator 1 (F1) em negrito, localiza-se no eixo horizontal à direita e à esquerda.

Fator 2 (F2), em itálico, localiza-se no eixo vertical superior e inferior

Variáveis de Opinião ou Estímulos indutores. O número no final de cada palavra significa: 1 = surdo; 2 = Libras; 3 = inclusão do surdo; $4=$ inclusão da disciplina de Libras na escola.

Variáveis Fixas (em caixa alta e sublinhadas): alunos iniciantes, alunos concluintes e professores da educação básica.

Fonte: Autores. 
A leitura desta Figura 2 assinala variações semânticas na organização do campo espacial, revelando aproximações e distanciamento das modalidades nos dois fatores, representados no Fator 1 (F1) e Fator (F2). O somatório dos dois fatores demonstra um poder explicativo de $100 \%$ da variância total das respostas, demonstrando parâmetros estatísticos com consistência interna e fidedignidade.

Os resultados processados indicaram um somatório de 668 palavras, sendo 301 palavras diferentes, evocadas pelo conjunto dos participantes $(\mathrm{N}=50)$. Os alunos do primeiro período do curso de Pedagogia contribuíram com 397 palavras $(59,4 \%)$, os alunos concluintes com 230 palavras $(34,4 \%)$ e os professores do ensino fundamental I com 41 palavras $(6,1 \%)$.

Através do plano, verifica-se que o primeiro fator (F1), destacado em negrito na linha horizontal, expôs as maiores cargas fatoriais, explicando 72,3\% da variância total de respostas dos dois grupos de estudantes universitários.

Neste eixo, a direção negativa do gráfico (à esquerda) revela as variáveis de opinião explicitadas pelos alunos concluintes do curso de Pedagogia. Para esse grupo, o primeiro estímulo, pessoa surda, sinônimo de pessoa que não escuta, possui limitações e necessita de cuidado e atenção. Portanto, para esse grupo a pessoa surda é alguém com limitações que necessita de cuidado e atenção para sobreviver. Em alguns casos, houve uma visibilidade de que o surdo é um ser incapaz quando, na verdade, ele apenas não possui um dos sentidos, podendo perfeitamente desenvolver suas capacidades cognitivas através dos demais sentidos formando sua própria identidade.

Brito (1993) assegura que o surdo é dotado de capacidades, possuindo potenciais assim como nós, ouvintes. É a partir da sua língua materna, a Libras, que eles desenvolvem todo esse processo. As evocações do próximo estímulo, Libras, foi objetivada como linguagem de sinais, ensino e ajuda. A Libras, por sua vez, é considerada uma língua pois, assim como explica Veodato e Vágula (2014), possui um sistema de regras gramaticais com diversos planos: fonológico, morfológico, sintático e frasal.

No terceiro estímulo indutor, inclusão social do surdo, o surdo foi representado pelos concluintes como pessoas que sofrem preconceito na sociedade. Essas observações podem ser confirmadas por Gesser (2009), que descreve diversas manifestações preconceituosas e excludentes sofridas pelos surdos ao longo da história.

A evocação inclusão da disciplina da Libras nas escolas foi representada por estes alunos como uma disciplina de conhecimento e inclusão que objetiva interação e respeito para com os surdos, na qual a inclusão se configura como benefício não só para a comunidade surda, como também para os ouvintes, ao possibilitar a aquisição de uma nova língua.

Desse modo, podemos concluir que para esse grupo de sujeitos, o surdo necessita da Libras enquanto língua materna, principal instrumento que fundamenta o seu desenvolvimento e a sua inclusão na sociedade. A aquisição e o uso da língua ainda sofrem ataques originados do preconceito e da exclusão, de modo que a disciplina Libras, mesmo não sendo a solução, representa mais um passo fundamental para que o sujeito acometido pela surdez tenha vez e "voz" na sociedade. Silva e Nembri (2008) argumenta que a partir do conhecimento da cultura do outro é possível entender suas dificuldades e necessidades, bem como aprender essa nova língua que é a Libras.

Ainda no F1, ao lado direito, situa-se o campo semântico elaborado pelos alunos iniciantes. Segundo estes discentes, o surdo é representado como uma pessoa deficiente. O segundo estímulo Libras foi representado por esses participantes como produzida pelas mãos. E o estímulo seguinte, inclusão social do surdo, foi representado através da amizade. A última evocação, inclusão da disciplina de Libras nas escolas, foi representada como aprendizado que favorece a valorização. Nessa concepção, os alunos iniciantes, por sua vez, destacam que o surdo é um deficiente auditivo que se comunica através das mãos e que a inclusão do surdo se configura em laços de amizade.

Veodato e Vágula (2014) afirmam que a língua de sinais se configura como espaço-visuais, diferenciando-se da língua portuguesa e, através dela, como argumenta Skliar (1997), a Libras é o elemento mediador entre o surdo e o meio social. Em 
vista disso, a inclusão da disciplina de Libras nas escolas é considerada como um instrumento inclusivo e necessário no processo de ensino-aprendizagem.

No fator destacado em itálico (F2), na linha vertical do plano, com um percentual de 27,7\% da variância total de respostas, evidenciam-se dois campos semânticos distintos. No primeiro, apresentado no campo superior do gráfico, não foram observados no plano fatorial de correspondência qualquer evocação proferida por nenhum dos participantes.

Distintamente, no plano inferior, identificam-se as livres associações do grupo dos professores da educação básica. Para estes docentes, o surdo foi caracterizado como sujeito que utiliza a comunicação através de Libras. Quanto ao estímulo Libras, os docentes relacionaram-no à linguagem gestual. O terceiro estímulo, inclusão social do surdo, foi reconhecido como um direito a ser efetivado no cenário brasileiro.

A quarta e última evocação, inclusão da disciplina de Libras nas escolas, foi representada como educação e comunicação. Tal como afirma Silva (2016) sobre a inclusão da disciplina de Libras: "a possibilidade de oferecer aos alunos contato com uma nova cultura a fim de fazê-los compreender a sua e a do outro, para assim agir no mundo sob uma perspectiva crítica" (p. 57), esses participantes a consideram um avanço na educação, que possibilitará, efetivamente, a comunicação entre surdos e ouvintes.

Os resultados indicam que a surdez, Libras, inclusão do surdo e inclusão da disciplina de Libras nas escolas se configuram como um fenômeno multifacetado, perpassado por inúmeras dificuldades, lutas e conquistas, mas que ainda não fomentaram discussões e práticas suficientes no que diz respeito à inclusão.

Desse modo, para o grupo dos docentes observamos a ausência de conhecimento em relação ao sujeito surdo, bem como à inclusão da disciplina de Libras na escola e, consequentemente, a integração do surdo na sociedade. É perceptível que, à exceção de um ou dois participantes, os demais não estão preparados para receber um surdo em sala de aula. Ciente disso, detectamos uma problemática da educação que repercute ao longo dos anos: a falta de capacitação dos docentes, que tendem a permanecer inertes no que concerne às metodologias de ensino. Nesse sentido, esta pesquisa não visou, tão somente, obter resultados, mas também investigar e buscar soluções viáveis para incluir o surdo em nossa sociedade através da inclusão da disciplina de Libras nas escolas, com o objetivo de reconstituir a sociedade, modificar e retocar o que foi tocado e deixado de lado (Moscovici, 2012).

A partir da leitura e análise dos resultados obtidos, compreendemos que os alunos concluintes, mesmo contribuindo com uma quantidade menor de palavras em comparação aos alunos iniciantes, têm uma percepção mais ampla no que se refere ao surdo e a Libras, o que pode ser explicado devido à presença de uma disciplina específica da língua presente na grade curricular. Daí a importância de incluir a Língua Brasileira de Sinais nas escolas, tanto para a diminuição das práticas discriminatórias, quanto para a inclusão do surdo na sociedade, enxergando-o enquanto sujeito igualmente capaz de se desenvolver, se habilitar e fazer escolhas.

Os alunos iniciantes que, por sua vez, contribuíram com a maior quantidade de palavras na pesquisa, têm uma visão limitada. Ademais, um grupo seleto de estudantes se dispuseram a responder o questionário, representando a falta de interesse de uma parcela maior da sociedade pelos temas que discutem a inclusão.

Nesse seguimento, podemos aferir que, mesmo que os alunos iniciantes não possuíssem pleno domínio do tema, quando questionados, foram automaticamente direcionados à reflexão e discussão, gerando interesse e necessidade em aprofundar os conhecimentos e, até mesmo, considerar o estudo de Libras. Eles conseguiram identificar a importância da capacitação profissional enquanto futuros pedagogos, bem como Félix e Santos (2011) afirmam que, através do estudo das representações sociais acerca do objeto estudado, é possível identificar os problemas, sejam físicos ou intelectuais de cada grupo com suas características singulares a respeito do tema da pesquisa trazendo novas reflexões. 


\section{Considerações Finais}

O presente trabalho teve como objetivo principal apreender as representações sociais dos alunos e professores da educação básica do Município de Guarabira/PB no que diz respeito à inclusão da disciplina Libras nas escolas. Relacionando benefícios e desafios para a educação, foi perceptível o despreparo da maioria dos participantes, bem como a falta de conhecimento acerca do sujeito surdo.

Concluímos que os objetivos da pesquisa foram alcançados, de modo a perceber a realidade da educação, bem como de nossa sociedade. Através de questionamentos e informações relevantes direcionadas aos sujeitos, estes foram capazes de entrar em contato com a temática abordada a partir de discussões sobre a importância da Libras, bem como a necessidade da inclusão do surdo na sociedade.

Diante disso, o presente estudo contribui no sentido reiterar a importância da inclusão da disciplina de Libras. Além disso, acredita-se que esse estudo poderá contribuir para um maior aprofundamento nos estudos sobre a surdez e da teoria das representações sociais, bem como, para o conhecimento da teoria das representações sociais. Além de apresentar um debate importante e gerar reflexões consideráveis acerca da Libras.

Não obstante, é indispensável destacar algumas limitações que foram percebidas durante pesquisa: (1) número reduzido da amostra; e (2) a amostra ampliada para outros estudantes e educadores. Podemos ainda aferir que, em alguns levantamentos informais durante a pesquisa, percebeu-se que nas escolas a inclusão dessa disciplina fica a cargo do gestor. Dessa forma, consideramos lastimável perceber que a maioria dos gestores não estão realmente capacitados para esse cargo, ignoram a oportunidade de incluir a Libras, desconsiderando as contribuições efetivas que esta proporcionaria a nossa sociedade.

Dessa forma, espera-se que novos estudos sejam realizados, levando em consideração outras amostragens exemplo: professores de Libras, gestores e equipe técnica da escola, em outras regiões, a fim de que os resultados aqui encontrados possam ser confirmados, ou mesmo que possam fomentar a comparação entre grupos e regiões no que diz respeito à percepção sobre a inclusão da disciplina da Língua Brasileira de Sinais (Libras) nas escolas.

\section{Referências}

Abric, J. C. (1994). Pratiques sociales et représentations. Presses Universitaires de France.

Brasil (2002). Lei nº 10.436 de 24 de abril de 2002. (Dispõe sobre a Língua Brasileira de Sinais - Libras e dá outras providências). Presidência da República. Casa Civil. http://www.planalto.gov.br/ccivil_03/leis/2002/110436.htm

Brito, L. F. (1993). Integração social e educação de surdos. BABEL Editora.

Castro, M. G. F. (2016). Representação Social da Libras por sujeitos surdos bilíngues. IV Seminário Internacional Inclusão em Educação: Universidade e Participação, inclusão, ética e interculturalidade, Rio de Janeiro, Brasil. https://eventos.ufrj.br/evento/iv-seminario-internacional-inclusao-em-educacao/

Cibois, U. F. R. (1995). Tri-deux-mots. Versão 2.2 Sciences Sociales.

Costa, S. S. C., \& Kelman, C. A. (2013). Representações sociais dos surdos do curso de graduação em Letras-Libras. Revista Educação Especial, 26, (46), 437-450. http://dx.doi.org/10.5902/1984686X

Coutinho, M. P. L., \& Saldanha, A. A. W. (2005). Representações Sociais e Práticas de Pesquisa. Editora Universitária/UFPB.

Coutinho, M. P. L. (2005). Depressão Infantil e Representação Social. Ed. Universitária UFPB.

Creswell, J. W. (2010). Projeto de pesquisa: métodos qualitativo, quantitativo e misto. Artmed.

Davis, H., \& Silverman, S. R. (1970). Audição e Surdez. Rinehart and Winston.

Di Giacomo, J. P. (1981). Aspects méthodologiques de l'analyse des représentations sociales. Cahiers de Psychologie Cognitive, 1(1), 397-422.

Félix, L. B., \& Santos, M. F. S. (2011). A velhice na mídia escrita: um estudo em representações sociais. RBCEH, 8 (3), $363-374$.

Fernandes, E. (2003). Linguagem e surdez. Artmed.

Gesser, A. (2009). LIBRAS? Que língua é essa? Crenças e preconceitos em torno da língua de sinais e da realidade surda. Parábola. 
Gilly, Michel. (2001). As representações sociais no campo da educação. Em: Jodelet, D. As representações sociais. EdUERJ.

Jodelet, D. (2001). As representações sociais. EDUERJ.

Junqueira, A. E. S. Algumas representações sociais do instrutor de libras na educação de surdos em Gado Bravo-PB. Congresso Internacional de Educação e inclusão, Campina Grande, Paraíba, Brasil. https://www.editorarealize.com.br/editora/anais/cintedi/2014/Modalidade_1datahora_14_11_2014_1 9_17_50_idinscrito_5327_755c37904d0e1bdc1248be9adba0f660.pdf

Lafon, J. C. (1989). A deficiência Auditiva na Criança. Manole.

Minayo, M. C. de S. (2002). O desafio da pesquisa social. Em: Deslandes, S. F.; Gomes, R. \& Minayo, M. C. S. (Org). Pesquisa social: teoria, método e criatividade. Vozes.

Minayo, M. C. S. (2008). O conceito de representações sociais dentro da Sociologia clássica. Em: P. A. Guareschi e S. Jovchelovitch (Orgs.). Textos em representações sociais. (pp. 89-111). Vozes.

Moscovici, S. (2008). O conceito de Representações sociais dentro da sociologia clássica. Em: Guareschi, P. \& Jovchelovitch, S. (Orgs). Textos em representações sociais. Vozes.

Moscovici, S. (2012). A Psicanálise, sua Imagem e seu Público. Vozes.

Nóbrega, S. M., \& Coutinho, M. P. L. (2003). O Teste de Associação Livre de Palavras. Em: Coutinho, M. P. L. \& Cols. Representações Sociais: abordagem interdisciplinar (pp.67-77). Universitária UFPB.

Oliveira. L. A. (2012). Fundamentos Históricos, Biológicos e Legais da Surdez. IESDE Brasil S.A.

Organização mundial da saúde, (2000). Retardamento Mental: enfrentando o desafio. Washington DC: Organização Mundial da Saúde.

Quadros, R. M., \& Karnopp, L. B. (2004). Língua de Sinais Brasileira: Estudos linguísticos. Artmed.

Sá, C. (2001). Núcleo Central das Representações Sociais. Vozes.

Sá, C. (1998). A construção do objeto de pesquisa em representações sociais. EdUERJ.

Sá, N. R. L. (2002). Cultura, poder e educação de surdos. Universidade Federal do Amazonas.

Saraiva, E. R. de A. (2010). Violência contra idosos: aproximações e distanciamentos entre a fala do idoso e o discurso da mídia impressa. Tese de Doutorado em Psicologia Social. Universidade Federal da Paraíba, João Pessoa.

Saraiva, E. R. A. (2007). A experiência materna mediada pela depressão pós-parto: um estudo das representações sociais (Dissertação de Mestrado). Universidade Federal da Paraíba, João Pessoa, Brasil.

Sêga, R. A. (2000). O conceito de representação social nas obras de Denise Jodelet e Serge Moscovici. Anos 90. Porto Alegre, 13, 128-133. http://www.ufrgs.br/ppghist/anos90/13/13art8.pdf

Silva, A. C., \& Nembri, A. G. (2008). Ouvindo o silêncio: educação, linguagem e surdez. Mediação.

Silva, M. P. S. (2016). Inclusão de libras como disciplina no ensino fundamental. Prospectiva.

Skliar, C. (1997). Uma análise preliminar das variáveis que intervêm no Projeto de Educação Bilíngüe para os Surdos. Espaço Informativo Técnico Científico do INES, 6(1), 49-57.

Souza, L. L. \& Silva, L. V. L. (2018). Representações sociais sobre os artefatos da cultura surda. Revista TCBRASIL, 2(1), 384 - 403.

Vagula, E., \& Veodato, S. C. M. (2014). Educação inclusiva e língua brasileira de sinais. UNOPAR. 